\title{
Pseudomonas syringae Strains Naturally Lacking the Classical $P$. syringae hrp/hrc Locus Are Common Leaf Colonizers Equipped with an Atypical Type III Secretion System
}

\author{
Christopher R. Clarke, ${ }^{1}$ Rongman Cai, ${ }^{1}$ David J. Studholme, ${ }^{2}$ David S. Guttman, ${ }^{3}$ and Boris A. Vinatzer ${ }^{1}$ \\ ${ }^{1}$ Department of Plant Pathology, Physiology, and Weed Science, Virginia Tech, Latham Hall, Ag Quad Lane, Blacksburg, \\ 24061, U.S.A.; ${ }^{2}$ Sainsbury Laboratory, Norwich NR4 7UH, U.K.; ${ }^{3}$ Centre for the Analysis of Genome Evolution \& Function, \\ University of Toronto, Toronto, Ontario, M5S3B2 Canada
}

Submitted 30 June 2009. Accepted 24 September 2009.

\begin{abstract}
Pseudomonas syringae is best known as a plant pathogen that causes disease by translocating immune-suppressing effector proteins into plant cells through a type III secretion system (T3SS). However, $P$. syringae strains belonging to a newly described phylogenetic subgroup (group 2c) are missing the canonical $P$. syringae hrp/hrc cluster coding for a T3SS, flanking effector loci, and any close orthologue of known $P$. syringae effectors. Nonetheless, $P$. syringae group 2c strains are common leaf colonizers and grow on some tested plant species to population densities higher than those obtained by other $P$. syringae strains on nonhost species. Moreover, group 2c strains have genes necessary for the production of phytotoxins, have an ice nucleation gene, and, most interestingly, contain a novel $h r p / h r c$ cluster, which is only distantly related to the canonical $P$. syringae hrp/hrc cluster. This $h r p / h r c$ cluster appears to encode a functional T3SS although the genes $h r p K$ and $h r p S$, present in the classical $P$. syringae $h r p / h r c$ cluster, are missing. The genome sequence of a representative group 2c strain also revealed distant orthologues of the $P$. syringae effector genes $a v r E 1$ and hopMI and the $P$. aeruginosa effector genes exoU and exoY. A putative life cycle for group $2 \mathrm{c} P$. syringae is discussed.
\end{abstract}

Bacteria in the Pseudomonas syringae group are plant pathogens that cause diseases known as bacterial blight, spot, speck, stripes, and canker (Agrios 1997). Although the host range of this group of bacteria includes the majority of crops and ornamental plants, the host range of individual strains of $P$. syringae is generally restricted to one or a small number of known plant species. When environmental conditions are favorable, $P$. syringae may enter host leaves through wounds or stomata, multiply exponentially, and cause disease. However, some $P$. syringae strains have been found to survive on leaf surfaces for extended periods of time as epiphytes without causing any disease symptoms, and, even apparently host-specific strains have been isolated from nonsymptomatic weeds near crop fields (McCarter et al. 1983), suggesting that $P$. syringae strains can grow, or at least survive, on plants on which they do not cause disease (Lindow 1985; Hirano and Upper 2000).

Corresponding author: Boris A Vinatzer; E-mail: vinatzer@vt.edu

* The $\boldsymbol{e}$-Xtra logo stands for "electronic extra" and indicates six supplementary figures and two supplementary tables are published online.
One of the ways in which $P$. syringae strains seem to facilitate their own entry into leaves is by causing frost damage through catalyzing the freezing of water with an ice nucleation protein (Lindow et al. 1982). After growing to high number within leaves, disease symptoms are believed to aid $P$. syringae to erupt back to the leaf surface to be transmitted to new plants (Hirano and Upper 2000). Recently, evidence accumulated that $P$. syringae bacteria can be transmitted to geographically distant plants by being transported with air currents to clouds and coming back to the earth surface with rain and snow (Morris et al. 2008). Possibly, some $P$. syringae strains facilitate their return to earth by again taking advantage of their ice nucleation protein to catalyze ice crystal formation in clouds, which will give rise to rain drops and snow flakes.

The best-studied section of the $P$. syringae life cycle is its exponential endophytic growth phase between entry into leaves and the appearance of disease symptoms. To accomplish this part of its life cycle, $P$. syringae suppresses the plant innate immune system triggered by microbe-associated molecular patterns (MAMPs), such as the flg22 epitope of the flagellin protein (Zipfel et al. 2004), by translocating immune-suppressing effector proteins through a type III secretion system (T3SS) into plant cells (Zhou and Chai 2008). Although effector proteins suppress immunity in some plants, in other plants, they trigger the plant immune system (effector triggered immunity [ETI]) (Chisholm et al. 2006) upon their recognition by cognate resistance proteins which, in turn, activate a secondary defense reaction termed the hypersensitive response (HR) (Greenberg and Yao 2004). Therefore, effectors represent a double-edged sword, allowing growth on some plant species while interfering with it on others. Thus, optimizing effector repertoires for maximum virulence on host plant species may exclude other plant species from the host range and effectors may be the main reason for the narrow host range of most $P$. syringae strains.

The T3SS is encoded by a cluster of hrp/hrc genes, sonamed because their mutation abolishes the HR and pathogenicity, whereas some genes are conserved among a broad range of T3SS-harboring bacteria (Huang et al. 1993). Some effectors are encoded by loci flanking the $h r p / h r c$ locus. The conserved effector locus (CEL) (Alfano et al. 2000) is composed of the effector genes hopM1 and avrE1, with demonstrated roles in suppressing plant immunity (DebRoy et al. 2004) and of $h r p W$, which encodes a T3SS-secreted helper protein that targets the plant cell wall (Charkowski et al. 1998). The exchange- 
able effector locus (EEL) (Alfano et al. 2000) encodes effectors that vary among strains (Charity et al. 2003; Deng 2003). Other loci containing effectors are distributed throughout the $P$. syringae genome (Lindeberg et al. 2008). Besides effectors, some $P$. syringae strains also produce phytotoxins that play a facultative role in the disease process (Bender et al. 1999).

We recently reported the existence of a small phylogenetic subgroup of $P$. syringae strains that do not induce an HR and do not cause disease on any tested plant species (Mohr et al. 2008), supporting the hypothesis that some $P$. syringae strains are nonpathogenic (Lindow 1985; Hirano and Upper 2000). This group included PsyTLP2 and Psy508, reported previously to be nonpathogenic (Lindow 1985; Burr et al. 1996). Based on several molecular analyses, bacteria in this group have neither the canonical $P$. syringae T3SS nor orthologues of known $P$. syringae effectors. In particular, sequencing the $h r p / h r c$ locus and flanking effector loci in one of these strains, Psy508, we found that this entire genomic region only contained two hypothetical genes with similarity to two genes in the EEL of the tomato and Arabidopsis thaliana pathogen strain $P$. syringae pv. tomato DC3000 (PtoDC3000) (Buell et al. 2003). However, these two genes do not have any features predictive of being T3SS effectors. As expected, Psy508 was unable to translocate the effector AvrRpt2 into A. thaliana expressing the cognate resistance gene RPS 2 and induce an HR (Mindrinos et al. 1994). Intriguingly, however, Psy508 expressing AvrRpt2 triggered small HR-resembling specks in Nicotiana benthamiana, suggesting limited translocation of AvrRpt2 through the flagellum or through a T3SS encoded by genes too different from the canonical $P$. syringae hrp/hrc cluster to be detected by the employed molecular tests.

Here, we show that Psy508-like strains are very common leaf colonizers of healthy plants. Based on multilocus sequence analysis (Maiden et al. 1998; Gevers et al. 2005), these strains form a distinct $P$. syringae clade and grow as well as or better than other $P$. syringae strains on nonhost species without causing disease. Psy508-like strains contain an unusual hrp/hrc cluster that is only distantly related to the canonical $P$. syringae $h r p / h r c$ cluster. The encoded T3SS appears to be constitutively expressed and functional but not to play a major role during in planta growth. A hypothetical life cycle for this novel $P$. syringae group is described.

\section{RESULTS}

\section{Psy508-like strains are common leaf colonizers and constitute a monophyletic group within the $P$. syringae species complex.}

We previously reported (Mohr et al. 2008) that Psy508 isolated from a fallen apple leaf (Burr et al. 1996), PsyTLP2 isolated from a healthy potato leaf (Lindow 1985), three $P$. syringae strains from healthy Primula spp. in France, and two strains from unidentified healthy weeds in Virginia are all missing the canonical $P$. syringae hrp/hrc cluster, do not cause an HR on tobacco, and are more closely related to each other than to any other $P$. syringae strain analyzed by Hwang and associates (2005). To determine how common bacteria from this group are compared with other $P$. syringae bacteria that have a classic $h r p / h r c$ cluster, $P$. syringae bacteria were isolated from leaves of random weeds and bushes in southwestern Virginia and West Virginia in spring 2008 (Table 1). All sampled plants had no visible disease symptoms and belonged to at least six distinct plant families (Rosaceae, Solanaceae, Plantaginaceae, Lamiales, Primulaceae, and Ranunculaceae). Several plants could not be identified because no flowers were present at the time of collection in early spring. Between one and several hundred colonies were isolated from surface-steril- ized leaf disks on medium selective for $P$. syringae (Mohan and Schaad 1987). A gyrB gene fragment of representative colonies was sequenced as described by Hwang and associates (2005). In total, 24 strains from 24 different plants were provisionally identified as $P$. syringae based on the fact that their gyrB sequence was most similar to a $P$. syringae strain in GenBank using the blastn algorithm (Altschul et al. 1997). Only two of these strains were positive for the $h r p / h r c$ region using hrp/hrc-specific polymerase chain reaction (PCR) primers (Mohr et al. 2008) (data not shown). The 22 strains that were negative for the $h r p / h r c$ region based on PCR were also negative for the HR when inoculated at an optical density at 600 $\mathrm{nm}\left(\mathrm{OD}_{600}\right)$ of 0.1 in leaves of cultivated tobacco (N. tabacum), in agreement with the absence of the $h r p / h r c$ cluster. However, when a subset of these strains was tested at higher concentrations of inoculum, some strains caused leaf collapse: four of 14 strains caused leaf collapse at an $\mathrm{OD}_{600}$ of 0.3 and seven of 14 caused leaf collapse at an $\mathrm{OD}_{600}$ of 0.6 (data not shown), suggesting that these strains produce either some kind of elicitor of plant defenses or phytotoxins that damage tissue integrity.

Multilocus sequence typing (MLST) based on four loci (Hwang et al. 2005) was performed on the 22 HR-negative strains and for one of the two strains found to have a $h r p / h r c$ cluster. The data for these strains and for the seven HR-negative strains described by Mohr and associates (2008) were added to the Plant Associated Microbes Database (PAMDB) (Almeida et al. in press). The four sequences were concatenated for each of the 30 strains and for all strains typed by Hwang and associates (2005), and a neighbor-joining tree was constructed (Fig. 1). All 29 putative $h r p / h r c$-negative strains were found to be more similar to each other than to any known pathogenic relative and to populate a distinct branch of the tree. The bootstrap support for this branch is only 39.3 but removing a single isolate, PsyTLP2, increases the bootstrap support to 82.3. Moreover, all 29 strains, including PsyTLP2, form a distinct clade when individual gene genealogies are

Table 1. Strains used in this study ${ }^{\mathrm{a}}$

\begin{tabular}{|c|c|c|c|}
\hline Isolate & Plant of isolation & Place of isolation & $\begin{array}{c}\text { Year of } \\
\text { isolation }\end{array}$ \\
\hline Psy508 & Malus $\times$ domestica & Geneva, NY & 1991 \\
\hline PsyTLP2 $^{c}$ & Solanum tuberosum & - & - \\
\hline Psy908 & Veronica officinalis & Blacksburg, VA & 2008 \\
\hline Psy907 & Glechoma hederacea & Blacksburg, VA & 2008 \\
\hline Psy897 & - & Blacksburg, VA & 2008 \\
\hline Psy909 & Physalis heterophylla & Blacksburg, VA & 2008 \\
\hline Psycc $1502^{\mathrm{d}}$ & Primula farinosa & France & - \\
\hline Psycc667 & Primula sp. & Jura, France & 2004 \\
\hline Psycc $1503^{\mathrm{d}}$ & Primula farinosa & France & - \\
\hline Psy914 & Ranunculus bulbosus & Blacksburg, VA & 2008 \\
\hline Psy892 & - & Blacksburg, VA & 2008 \\
\hline Psy895 & - & Blacksburg, VA & 2008 \\
\hline Psy872 & - & Athens, WV & 2008 \\
\hline Psy871 & - & Athens, WV & 2008 \\
\hline Psy645 & - & Blacksburg, VA & 2007 \\
\hline Psy912 & Plantago rugelii & Blacksburg, VA & 2008 \\
\hline Psy889 & - & Blacksburg, VA & 2008 \\
\hline Psy898 & - & Blacksburg, VA & 2008 \\
\hline Psy863 & - & Athens, WV & 2008 \\
\hline Psy884 & - & Roanoke, VA & 2008 \\
\hline Psy879 & - & Athens, WV & 2008 \\
\hline Psy642 ${ }^{\mathrm{d}}$ & - & Blacksburg, VA & 2007 \\
\hline Psy891 & - & Blacksburg, VA & 2008 \\
\hline Psy869 & - & Athens, WV & 2008 \\
\hline
\end{tabular}

${ }^{a}$ Strains with an unknown plant of isolation (-) all came from small newly emerging weedy plants in early spring.

${ }^{\mathrm{b}}$ Burr et al. 1996.

c Lindow 1985.

d Mohr et al. 2008. 


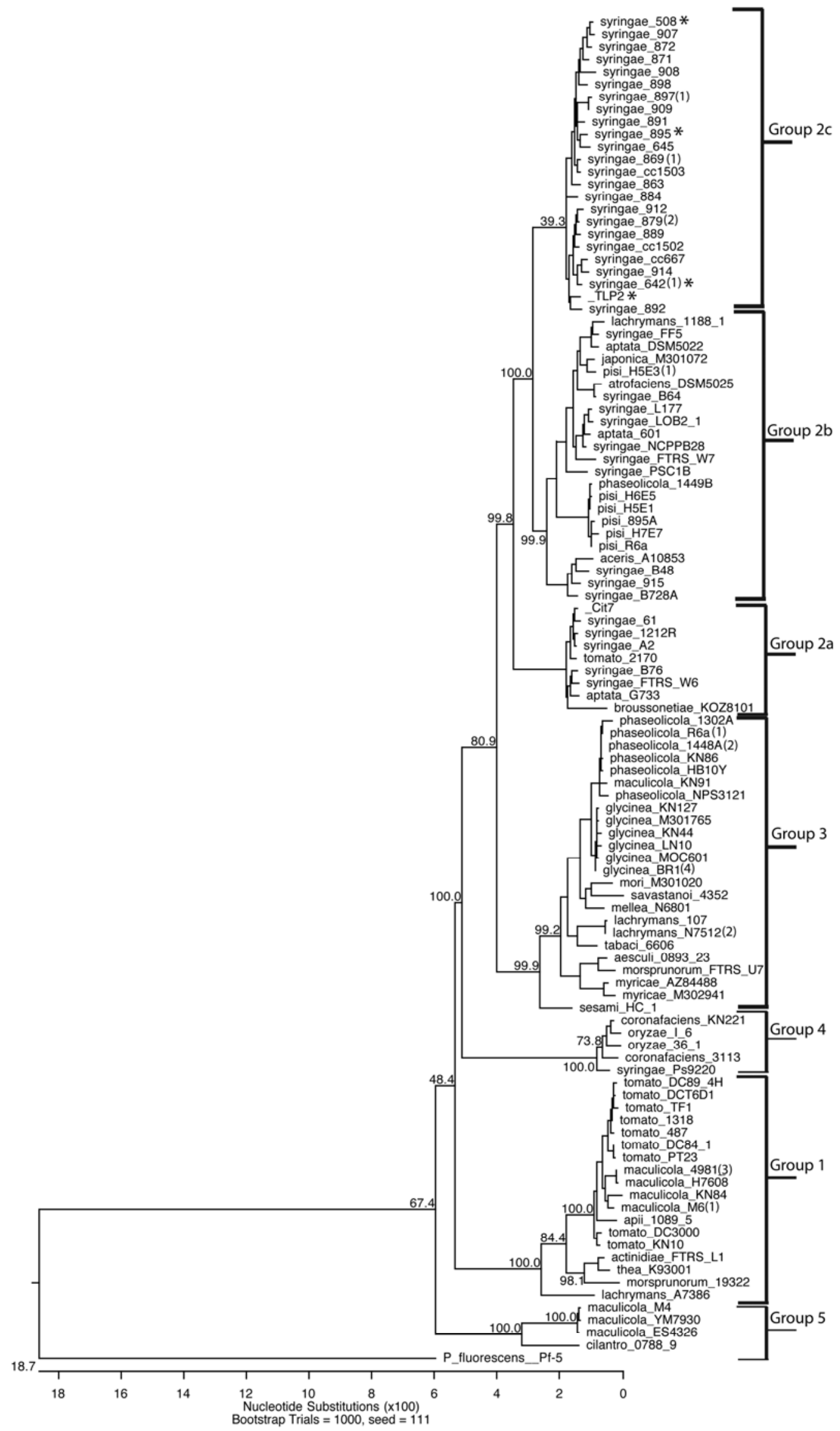

Fig. 1. Neighbor-joining tree of Pseudomonas syringae based on the concatenated data set of fragments derived from the four "housekeeping" genes: gyrB, rpoD, gltA, and gap1. All strains in group 2c are missing a classical P. syringae hrp/hrc cluster. Asterisk (*) indicates strains used for further characterization. Numbers in parentheses next to strain names indicate number of analyzed strains with sequences identical to the named strain. 
constructed for the four individual gene fragments (data not shown). Because this group of strains represents a separate phylogenetic group within phylogroup 2 (Hwang et al. 2005), the putative $h r p / h r c$-negative strains will be called group $2 \mathrm{c}$ strains hereafter. The other two major subgroups within phylogroup 2 have been named $2 \mathrm{a}$ and $2 \mathrm{~b}$. The bean pathogen PsyB728a (Feil et al. 2005) in group 2b is the closest known sequenced, pathogenic relative of group 2c $P$. syringae. The only $h r p / h r c$-positive strain that was typed was identical to Psycit7 in group 2a. Among all group 2c strains, there were only five instances of multiple strains having identical sequences across all four loci, indicating that the true diversity of this group is not fully enumerated.

\section{Group 2c $P$. syringae strains reach in planta population densities}

at least as high as other $P$. syringae strains on nonhosts.

The apparent lack of a classic T3SS in all group 2c strains suggested for these bacteria a life style different from that of well-characterized pathogenic $P$. syringae bacteria. Without a T3SS, they should be unable to translocate effectors into plant cells to suppress MAMP-triggered immunity (MTI) on host plants or elicit ETI (Jones and Dangl 2006) on nonhost plants. This suggests that they may not be pathogenic on any plant species and propagate better than pathogenic $P$. syringae strains on nonhosts (defined as plant species on which a strain does not cause disease) (i.e., is not virulent).

To test this hypothesis, four widely used model host plants of P. syringae were chosen: bean (Phaseolus vulgaris), tomato (Solanum lycopersicum), N. benthamiana, and A. thaliana. Four group 2c Pseudomonas syringae strains (Fig. 1, asterisk) repre- sentative of the diversity within group $2 \mathrm{c}$ were selected to infect the four plant species via spray infection (to mimic natural infections) at a bacterial concentration sufficient for a known pathogen to induce disease symptoms. As expected, the group $2 \mathrm{c}$ strains did not cause disease symptoms on any of the tested plant species even 7 days after infection (Supplementary Fig. 1). Furthermore, group 2c strains, unlike some of the tested known nonhost pathogens, did not elicit an HR, either (data not shown). Total bacterial population densities indicated that all of the tested group 2c strains are able to survive or propagate at least as well as nonhost pathogens on all four tested plants (Fig. 2). Note that day zero population densities are high because leaves were not sterilized prior to bacterial isolation (in order to include epiphytic populations). Therefore, bacteria sprayed on leaf surfaces are included in the measured population densities on day zero. On bean, 3 days postinoculation, three of four strains had multiplied approximately 100-fold and reached a population density similar to that of the snap bean pathogen PsyB728a, which was only slightly lower than the population size of the kidney bean pathogen Pph1448A; however, by day seven, their population sizes decreased almost to the level of the tomato pathogen PtoT1, which had a population size approximately 1,000-fold lower than that of Pph1448A. On $N$. benthamiana, group 2c strains multiplied approximately 100 -fold by day three postinfection and stayed at that level through day seven. Similar growth was observed for PtoT1 while PsyB728a, which is pathogenic on $N$. benthamiana, reached population sizes 100fold higher on both days. Group 2c strains were not able to propagate on either tomato or A. thaliana but were still able to perform similarly to the tested nonhost pathogen PsyB728a up to day three. The inability to grow in A. thaliana was also con-
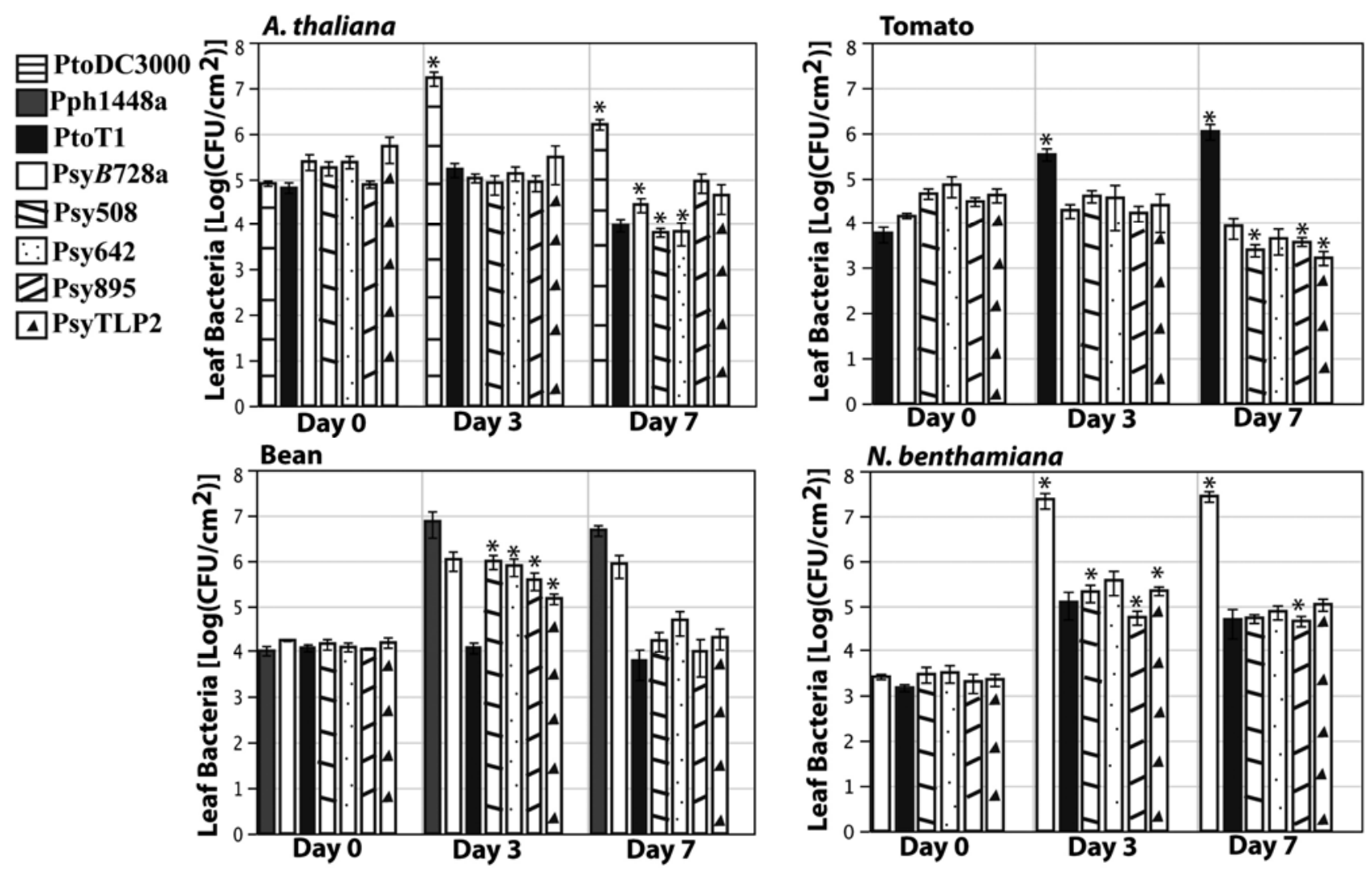

Fig. 2. Growth in planta of group 2c Pseudomonas syringae strains and host and nonhost pathogens on four plant species. Cv. Chico III was used for tomato and cv. Red Mexican was used for bean. Total population densities (epiphytic plus endophytic populations) were determined on day 0 , 3 , and 7 postinfection. The host pathogen is always the left-most bar in each graph and the nonhost pathogen is next to the host pathogen; except for bean, for which two pathogens (Pph1448A and PsyB728a) were tested. Asterisks indicate a statistically significant difference $(P<0.05$, student's $t$ test $)$ in population size within each strain compared with the corresponding strain at day 0 . Similar results were found in three independent experiments. 
firmed using a 100-fold lower infection dose (Supplementary Fig. 2). In tomato, on the other hand, a 10-fold lower infection dose allowed the strains to increase their population size slightly by day three (Supplementary Fig. 3). Group 2c P. syringae had been initially isolated from surface-sterilized leaf disks, suggesting an ability to enter leaves and to grow endophytically; therefore, endophytic and epiphytic population sizes were compared between the four representative group $2 \mathrm{c}$ strains and the pathogenic $P$. syringae strains used above. All four strains were found to be able to survive and grow endophytically better than the tested nonhost pathogens on bean, $N$. benthamiana, and, to a lesser extent, tomato, but not on A. thaliana (Supplementary Fig. 4 and data not shown). Therefore, although group 2c strains are apparently missing a T3SS and effector genes, they still demonstrate a certain degree of host specificity (or at least preference).

\section{A draft genome sequence of the group 2c isolate Psy642} reveals a noncanonical $P$. syringae T3SS.

To begin unraveling how group $2 \mathrm{c} P$. syringae bacteria are able to survive and even grow on some plant species, we se- quenced the genome of the group 2c isolate Psy642 using Illumina technology (Bentley 2006). The genome was assembled from 8,477,656 pairs of 42-nucleotide (nt)-long reads, giving an approximately 120 -fold theoretical genome coverage. The assembly consists of 488 contigs, with the longest contig being $135,361 \mathrm{nt}$ long, an $\mathrm{N}_{50}$ length of $26,055 \mathrm{nt}$, and an $\mathrm{N}_{50}$ number of 69 contigs (i.e., $50 \%$ of all nucleotides in the assembly are in 69 contigs that are longer than 26,055 nt). The total length of the assembly is $5,965,778 \mathrm{nt}$. The assembly can be searched using blast at the Vinatzer laboratory (Virginia Tech, Blacksburg, VA, U.S.A.). A Psy642 genome project was submitted to GenBank (Project ID: 40347) and the genome sequence will be deposited and annotated in GenBank after improving the assembly with additional reads in the future.

To determine how genetically similar Psy642 is to typical $P$. syringae strains, we compared the Psy642 sequence reads against the genome sequence of the closely related $P$. syringae pathogen PsyB728a (Feil et al. 2005). We used the program MAQ (Li et al. 2008) to align the Psy642 sequencing reads against the PsyB728a genome (Fig. 3A). Note that this align-
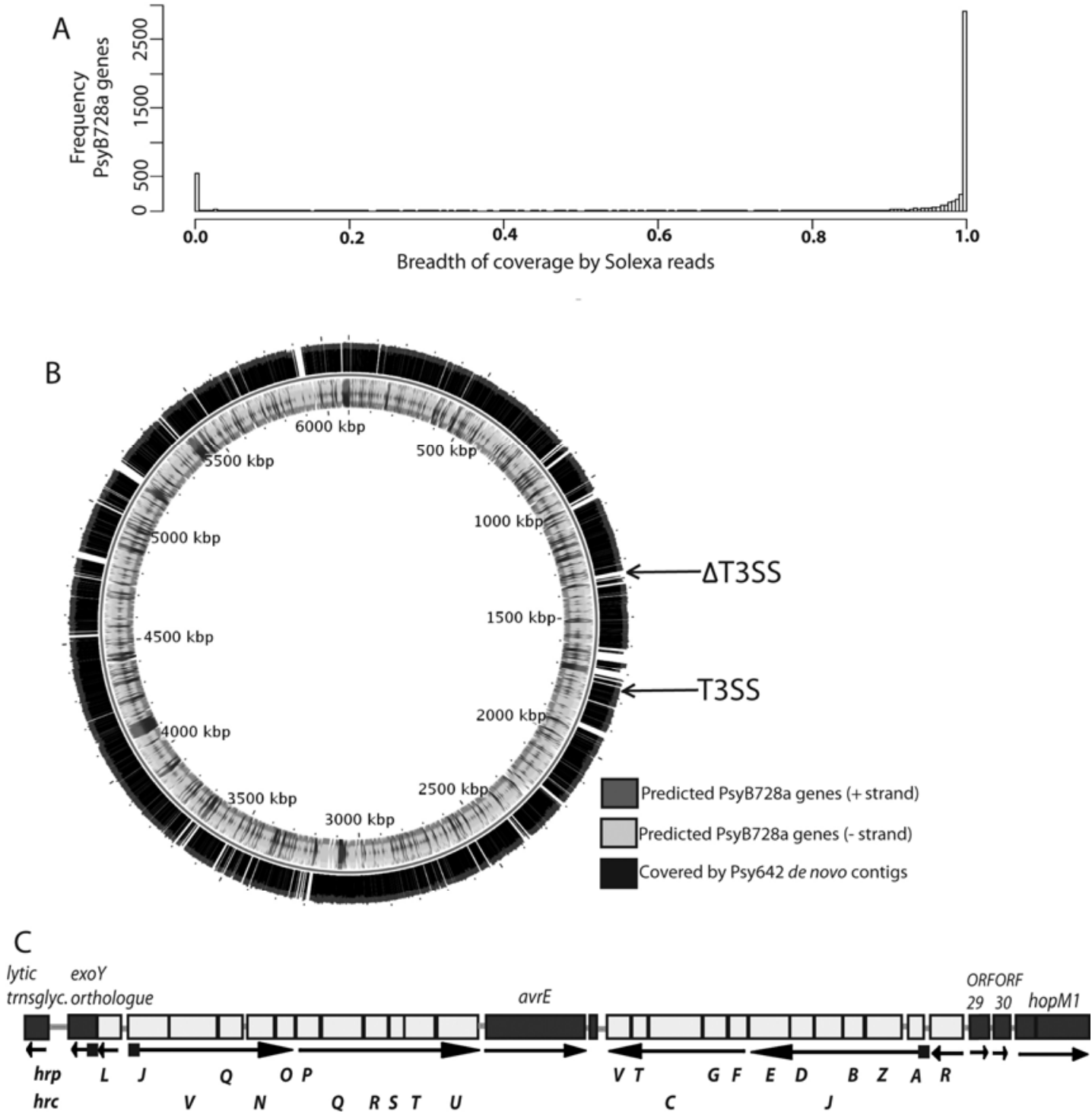

Fig. 3. Comparison of the Psy642 draft genome with the assembled PsyB728a genome. A, Histogram showing breadth of coverage of PsyB728a genes by Illumina sequencing reads of the Psy642 genome. B, Alignment of Psy642 de novo contigs (black ring) with the PsyB728a genome (genes are light gray or dark gray depending on gene orientation). The location of the canonical $h r p / h r c$ cluster in PsyB728a and the atypical $h r p / h r c$ cluster in Psy642 are indicated. C, Organization of the Psy642 hrp/hrc cluster and flanking regions. Open reading frames (ORF) of the type III secretion system components (white rectangles) and putative effectors (dark gray rectangles) are shown. Arrows indicate reading frame direction and black boxes indicate conserved Hrp boxes. 
ment approach does not rely on de novo assembly and, thus, is not affected by any assembly errors or artifacts. Of the 5,089 PsyB728a genes, 4,123 are covered by aligned Psy642 reads over at least $90 \%$ of their lengths. Of these, 3,142 genes are covered over $99 \%$ or more of their lengths. Considering that some regions of some genes are probably not sufficiently similar between PsyB728 and Psy642 to allow the 42-nt-long Psy642 Illumina reads to align, we consider most PsyB728a genes with over $90 \%$ coverage to be present in the Psy642 genome. This supposition was supported by the observation that, of 640 PsyB782a genes that are also highly conserved in PtoDC3000 and Pph1448A, 637 were covered for over $90 \%$ of their length by Psy642 reads. On the other hand, we found that 667 PsyB728a genes were covered by Psy642 reads over no more than $10 \%$, suggesting that these genes are most likely absent from Psy642. As a comparison, when aligning a similar number of Illumina reads of the tomato pathogen PtoMax13 against the genome of the closely related tomato and $A$. thaliana pathogen PtoDC3000 (Buell et al. 2003), 4,765 of the 5,475 PtoDC3000 chromosomal genes are covered to $90 \%$ or more (unpublished data). Therefore, we conclude that the overall difference in gene content between PsyB728a and Psy642 is comparable with the difference between two similarly related pathogenic $P$. syringae strains with different host range. We did not count Psy642 genes absent from PsyB728a because of the uncertainty of genes missing from the current assembly of Psy642.

When examining an alignment of the Psy642 sequencing reads against the PsyB728a genome, it becomes clear that several of the PsyB728a genes missing from Psy642 are organized in large clusters (Fig. 3B). One of these clusters is the $h r p / h r c$ cluster of PsyB728a (Supplementary Table 1, Psyr_1183 to Psyr_1226). The two genomes align up to the CEL of PsyB728a, and start aligning again after the EEL (Supplementary Fig. 5). In Psy642, the entire 40-kbp hrp/hrc cluster and flanking CEL and EEL are replaced with only $1.7 \mathrm{kbp}$ of DNA (GenBank accession number GQ268172). Of these $1.7 \mathrm{kbp}$ of nonaligning DNA, $1 \mathrm{kbp}$ has similarity to two hypothetical DC3000 EEL proteins that are not effectors. These are the same two EEL genes found at this locus in the group 2c isolate Psy508 (Mohr et al. 2008). The other 700 bp have no significant similarity to any sequence in GenBank.

Other than the $h r p / h r c$ cluster and the flanking effector loci, the largest PsyB728a region missing from Psy642 (Psyr_1492Psyr_1539) contains a copper resistance gene cluster, a heavy metal sensor and regulator, and type II secretion system proteins. The region from Psyr_2030 to Psyr_2045 that is also missing from Psy642 contains a gene cluster for the synthesis of fimbrial proteins. Other PsyB728a regions missing in Psy642 contain $\mathrm{ABC}$ transporters, type I secretion systems, a TonBdependent siderophore receptor, and all PsyB728a genes coding for type III secreted effectors. Many PsyB728a regions missing from Psy642 are bacteriophage genomes or other genomic islands containing mainly open reading frames (ORF) coding for hypothetical proteins.

However, the draft genome sequence of Psy642 did reveal a surprise: an atypical $h r p / h r c$ region inserted in a different genomic location compared with the conserved location of the canonical P. syringae hrp/hrc cluster (Fig. 3B). This hrp/hrc cluster is located between the orthologues of two neighboring PsyB728a genes, Psyr_1587 and Psyr_1588, which code for a bile acid/sodium symporter and a recombination associated protein, respectively. Also, in the other completely sequenced P. syringae genomes, PtoDC3000 and Pph1448A, these two genes flank each other directly. The region in Psy642 between the orthologues of the PsyB728a genes Psyr_1587 and Psyr1588 (GQ268170) is shown in Figure 3C. The hrp/hrc cluster in Psy642 shows synteny to the canonical $P$. syringae $h r p / h r c$ cluster (Fig. 3C) (Alfano et al. 2000). The main differences are that the Psy642 hrp/hrc cluster lacks hrpK, which is thought to encode a protein with a role in effector translocation (Petnicki-Ocwieja et al. 2005), and only has one response regulator. The typical $P$. syringae hrp/hrc cluster instead contains two response regulators, $h r p R$ and $h r p S$, which code for positive regulators of the sigma factor HrpL (Xiao et al. 1994), the master regulator of type III secretion in P. syringae (Xiao and Hutcheson 1994). We annotated the response regulator in the Psy642 hrp/hrc cluster as $h r p R$ because the gene sequence is more similar to $h r p R$ of PsyB728a than to $h r p S$. A gene coding for a protein with similarity to $\mathrm{HrpL}$ with a predicted sigma (54)-dependent promoter is present in the same position as in the classical $P$. syringae $h r p / h r c$ cluster. An additional difference consists of a 6,638-nt-long insert between $h r c U$ and $h r p V$ that encodes homologs of the effector AvrE1 and its chaperone AvrF1. This location of avrE1 and avrF1 is similar to the location of these genes in some $h r p / h r c$ clusters in $P$. viridiflava and $P$. cichorii (Araki et al. 2006).

In other $P$. syringae genomes, a Hrp box motif is found in the promoter regions of all operons that compose the $h r p / h r c$ cluster and upstream of practically all confirmed effector genes (Fouts et al. 2002). Hrp boxes are believed to be binding sites for the HrpL sigma factor (Xiao and Hutcheson 1994). We identified Hrp boxes that strongly resemble confirmed Hrp boxes in other $P$. syringae genomes using a hidden Markov Model based on an alignment of PtoDC3000 Hrp boxes (Studholme et al. 2009) only upstream of the C, J, and $\mathrm{Z}$ operons of the Psy642 hrp/hrc cluster (Fig. 3C; Table 2). The R and U operons have candidate Hrp boxes that only partially resemble the

Table 2. Putative Hrp boxes of the type III secretion system (T3SS) operons and putative effector orthologues in Psy642

\begin{tabular}{|c|c|c|c|}
\hline Gene, operon & Hrp box ${ }^{a}$ & Nucleotides between Hrp box and start codon1 & HMM score ${ }^{b}$ \\
\hline L operon & - & - & - \\
\hline $\mathrm{J}$ operon & TGGAACCG..14.. CCACACA & 32 & 28.75 \\
\hline U operon & TGGAACT ..19..GCGACAGA & 96 & - \\
\hline C operon & GGGAACG..5..GCAC & 53 & 26.92 \\
\hline Z operon & TGGAACCG..15.. CCACTCA & 72 & 27.58 \\
\hline $\mathrm{R}$ operon & GTCAAGCG..11.. CCAATAA & 41 & - \\
\hline avrE & GCGAACT ..14.. GGCAGCA & 107 & 27.10 \\
\hline hорM1 & GCAACCG..4.. GCAC & 25 & 16.86 \\
\hline T3SS ORF29-30 & TGACGC..12.. GCCACCA & 55 & 29.84 \\
\hline lytic transglycosylase & - & - & - \\
\hline exoU & - & - & - \\
\hline exoY & TGCAACG..16..CCACACA & 11 & 15.01 \\
\hline
\end{tabular}

${ }^{a}$ Dashes (-) indicate that no putative Hrp box could be identified

${ }^{\mathrm{b}}$ For comparison, the Hrp box of the avrPtol $1_{\mathrm{PtoDC} 3000}$ effector gene has an hidden Markov Model (HMM) score of 34.54 and the Hrp box of the hopI PtoDC3000 effector gene has a score of 15.30. Dashes (-) indicate that the respective Hrp box was only identified by eye but not using the Hrp box HMM. 
typical Hrp boxes in other $P$. syringae genomes (Table 2). When compared with the typical $P$. syringae Hrp box (Fouts et al. 2002), $G$ for $C$ and $C$ for $G$ substitutions appear to be common, which may indicate that HrpL of Psy642 has slightly different DNA binding specificity compared with HrpL of other $P$. syringae strains or that these operons are regulated independently of HrpL.

To determine the similarity between the individual components of the Psy642 T3SS and their counterparts in the canonical $P$. syringae T3SS, the protein sequence for each T3SS compo- nent in PsyB728a was searched against the genome of Psy642 using the tblastn algorithm (Supplementary Table 2). Percentage protein identity values ranged between 25 and $72 \%$ for the components for which any alignment was detected. The predicted HrpA protein could not be aligned at all and was exclusively predicted based on its expected location in respect to its flanking genes and the $14 \%$ Serine residues in the N-terminal 50 amino acids of the predicted protein. Most Psy642 hrp/hrc genes do not align at the DNA level with their PsyB728a hrp/hrc homologues, which explains why we could not detect this unusual

Table 3. Characteristics predictive of type III secretion of putative Psy642 effectors

\begin{tabular}{|c|c|c|c|c|c|}
\hline Name & Length (amino acids) & Serines $^{\text {a }}$ & Acidic residues $^{b}$ & Polar residues ${ }^{c}$ & Aliphatic residues ${ }^{d}$ \\
\hline HopM1 & 700 & 5 & 0 & 26 & Yes \\
\hline AvrE1 & 1,852 & 5 & 0 & 28 & Yes \\
\hline T3SS ORF29 & 222 & 10 & 0 & 30 & Yes \\
\hline T3SS ORF30 & 270 & 5 & 0 & 27 & Yes \\
\hline Lytic Transglycosylase & 191 & 2 & 0 & 16 & Yes \\
\hline ExoY & 319 & 7 & 0 & 25 & No \\
\hline ExoU & 629 & 3 & 1 & 26 & No \\
\hline
\end{tabular}

${ }^{a}$ Number of serines in 50 most N-terminal amino acids; over five is typical of type III-secreted effectors

${ }^{\mathrm{b}}$ Acidic residues in 12 most N-terminal amino acids; absence is typical of type III-secreted effectors.

${ }^{\text {c }}$ Polar amino acids in 50 most N-terminal amino acids; high number is typical of type III-secreted effectors.

${ }^{\mathrm{d}}$ Aliphatic residues in position 3 or 4; presence is typical of type III-secreted effectors.

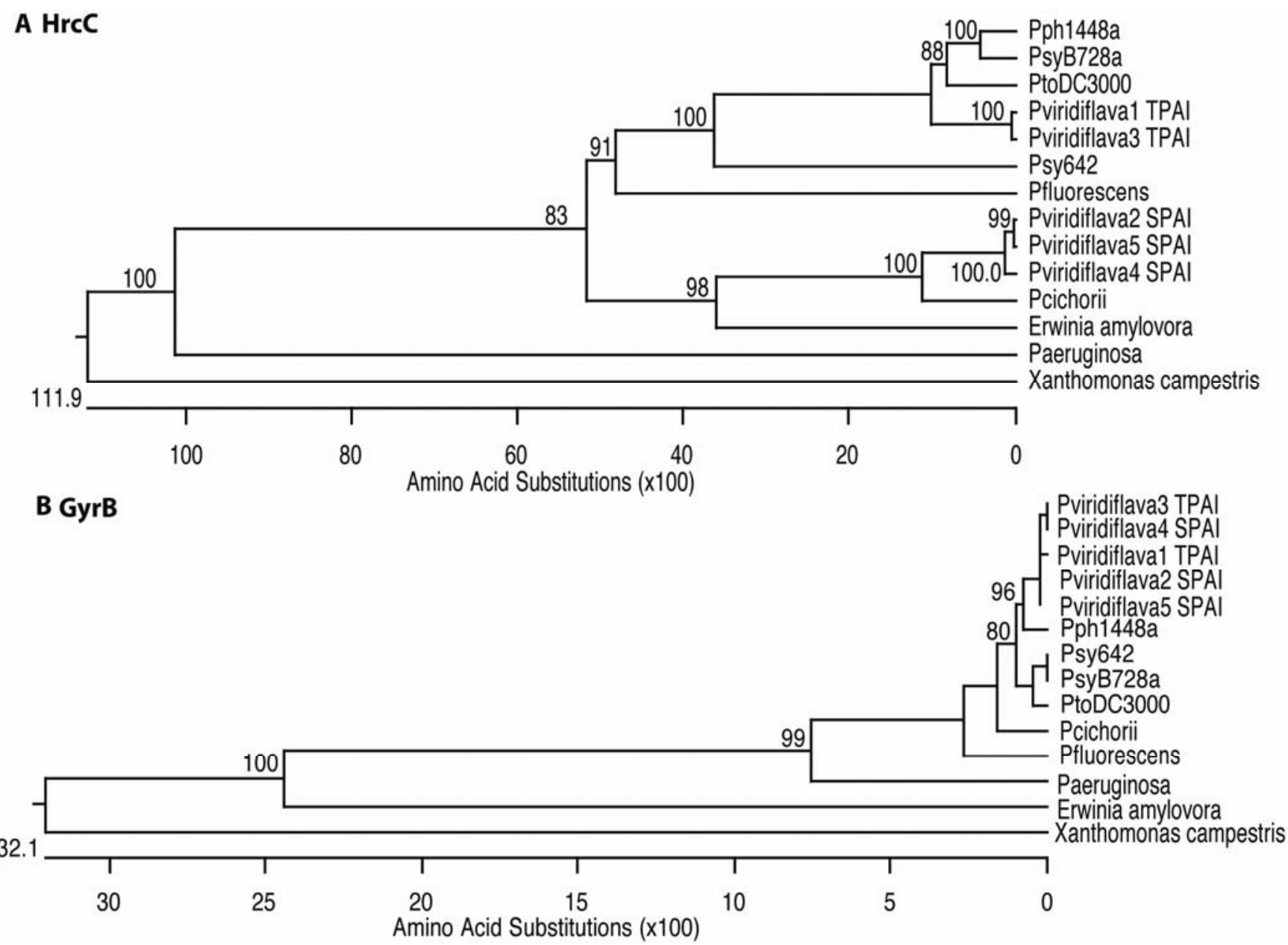

Fig. 4. Linearized neighbor-joining trees based on the protein sequences of $\mathbf{A}$, the conserved type III secretion system structural protein HrcC and $\mathbf{B}$, the housekeeping protein GyrB. Pseudomonas viridiflava 1 (strain p23.1a) and 3 (strain pna3.3a) have a tripartite pathogenicity island (T-PAI) and P. viridiflava 2 (strain me3.1b), 4 (strain rmx3.1b), and 5 (strain rmx23.1a) have an single (S)-PAI. Trees were midpoint rooted. Bootstrapping was performed for 1,000 trials and a random seed of 111. Sequences of strain PAO-1 were used for $P$. aeruginosa, sequences of strain 83-1 were used for $P$. cichorii, sequences of strain SBW25 were used for P. fluorescens, sequences of strain 85-10 were used for Xanthomonas campestris, and strain 321 was used for the HrcC sequence and strain NCPPB311 for GyrB sequence of Erwinia amylovora. 
hrp/hrc cluster by PCR or DNA/DNA hybridization in Psy508 (Mohr et al. 2008). As expected, the Hrc components of the T3SS, which are conserved between all described bacterial T3SS, were typically more conserved between PsyB728a and Psy642 than the Hrp components, which are specific to plantpathogenic Pseudomonads and Enterobacteriaceae.

To determine how common this noncanonical T3SS is among group 2c strains, all 29 group 2c strains were surveyed for the presence of the $h r c C_{\text {Psy642 }}$ gene by PCR using primers designed to anneal to $h r c C_{\mathrm{Psy} 642}$ but not to the $h r c C$ gene of the canonical $P$. syringae hrp/hrc cluster. All group 2c strains amplified a band of the expected size whereas no product was amplified when using any of the sequenced $P$. syringae pathogens as template (data not shown).

\section{Distant homologues of $P$. syringae and \\ $P$. aeruginosa effectors flank the Psy642 hrp/hrc cluster.}

In addition to avrEl located between $h r p V$ and $h r c U$, ORF for several other putative effectors were also identified flanking the Psy642 hrp/hrc cluster (Table 3). Homologues of hopM1 and its chaperone were found downstream of $h r p R$, as in the typical $P$. syringae CEL. Also, between $h r p R$ and hopMI are two small ORF that encode putative effectors based on a high $(>10 \%)$ serine content (Guttman et al. 2002) and a propensity for polar amino acids in the 50 most $\mathrm{N}$-terminal amino acids, absence of acidic residues in the first 12 amino acids, and an aliphatic amino acid in position 3 or 4 (PetnickiOcwieja et al. 2002). The two genes appear to be organized in an operon that is preceded by an upstream Hrp box (Table 2). Upstream of $h r p L$, in the region that corresponds to the EEL in typical $P$. syringae strains, is an ORF coding for a putative lytic transglycosylase and an ORF coding for a protein with similarity to the effector ExoY of the opportunistic animal pathogen $P$. aeruginosa (Yahr et al. 1998). The exoY homologue has a candidate Hrp box (Table 2) and satisfies all but one of the criteria for being a putative effector (Table 3). The Psy642 genome also has an ORF (GQ268171) encoding a protein with similarity $(e$ value $=1 \mathrm{e}-141)$ to the $P$. aeruginosa T3SS effector ExoU (Finck-Barbancon et al. 1997) in a different genomic location. However, there is no similarity between these two proteins in the 60 most $\mathrm{N}$-terminal amino acids, this protein has no features of a putative T3S effector (based on the criteria listed above) (Table 3), and no putative Hrp box pre-

Fig. 5. Tests for expression and function of the Psy642 hrp/hrc cluster. A, Luciferase activity of PsyB728a or Psy642 ectopically expressing the firefly luciferase gene under control of the avrPtol promoter in either rich or minimal medium. Bars represent total photons counted in $5 \mathrm{~min}$. All bacteria were diluted to 0.1 at an optical density of $600 \mathrm{~nm}$. Similar results were found in two independent experiments with three replicates each. B, Hypersensitive response (HR) test on Arabidopsis thaliana 'Col-0' RPS2 or the derived rps 2 mutant (Mindrinos et al. 1994). Psy642 ectopically expressing avrRpt2 (642 avrRpt2) from its chromosome on the integration vector pVT359 (Mohr et al. 2008) or 642 with the empty integration vector pVT138 (Mohr et al. 2008) (642 e.v.) were infiltrated into the left half of each leaf as indicated. Symptoms were assessed $24 \mathrm{~h}$ postinfection. Symptoms of a typical leaf are shown and the fractions indicate the number of infiltrated leaves that exhibited collapse of the entire infiltrated leaf area compared with the total number of infiltrated leaves. Similar results were obtained in three independent experiments. C, Two independent strains of Psy642 with a disruption in the $\mathrm{hrcC}$ gene (labeled as '642 $h r c C$-(1)' and '642 $h r c C$-(2)') and a strain of Psy642 with the empty integration vector pVT138 (Mohr et al. 2008) (labeled simply as 642) all expressing avrRpt2 from plasmid pLH12 (Whalen et al. 1991) were compared for HR induction. Similar results were obtained in two independent experiments. D, Nicotiana benthamiana leaves were inoculated with wild-type Psy642 and Psy642 hrcC-(1) and population densities were determined at 0 and 3 days postinfection. cedes this ORF. Therefore, if the Psy642 homologue of ExoU is secreted, it is likely through a type III-independent mechanism. The putative lytic transglycosylase, flanking the exoY homologue, also lacks features typical of T3SS effectors and no Hrp box is present. This is not surprising because, even in typical $P$. syringae strains, lytic transglycosylases do not act as true T3SS effectors but, rather, appear to play a role in aiding effector translocation through the periplasm (Oh et al. 2007).

No additional effector orthologues were identified when the Psy642 genome was searched with all described $P$. syringae, $P$. aeruginosa, and Xanthomonas spp. effector proteins using tblastn (Altschul et al. 1997) (data not shown). Effector sequences were obtained from the website for P. syringae and by
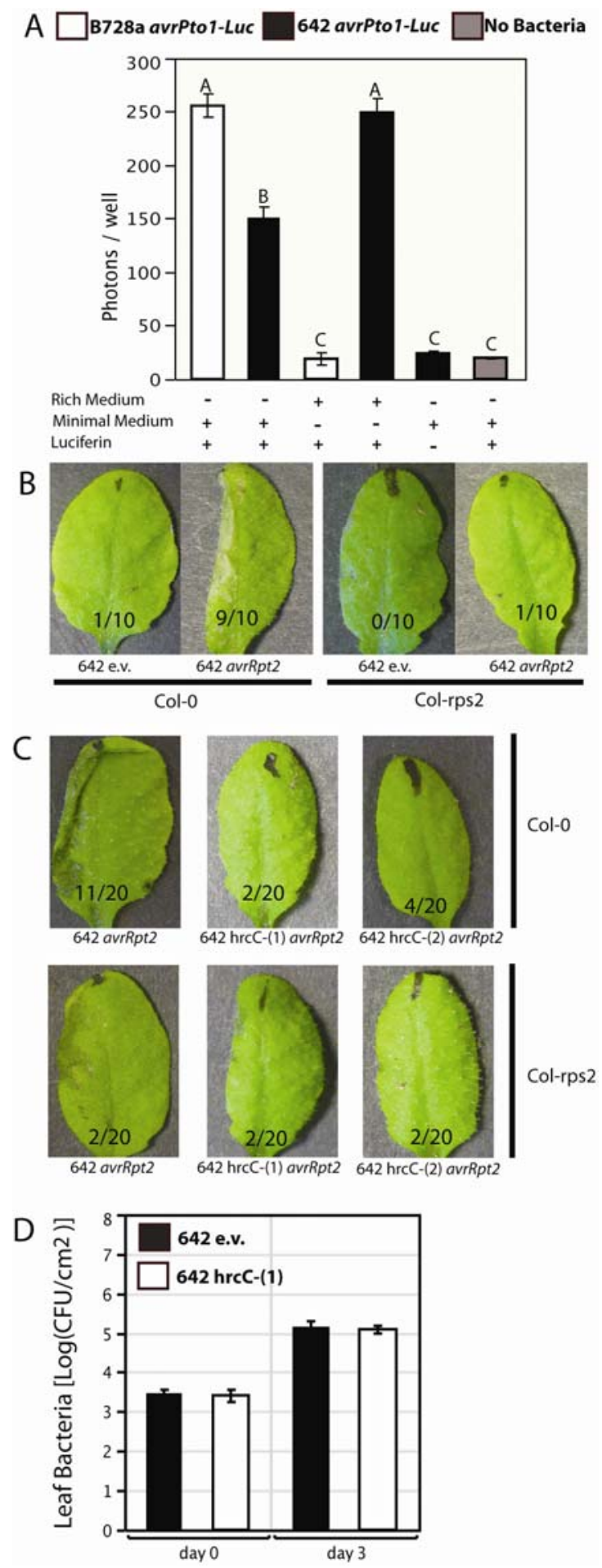

Vol. 23, No. 2, 2010 / 205 
searching GenBank for $P$. aeruginosa and Xanthomonas spp. effectors. Also, no other genes predicted in the Psy642 draft assembly and absent from PsyB728a (data not shown) revealed an obvious virulence mechanism that Psy642 could use to grow in plants other than the just described $h r p / h r c$ locus. Instead, genes shared between PsyB728a and Psy642 that are known to be important for the interaction of PsyB728a with plants include the biosynthetic genes for production of the toxins syringmomycin, syringopeptin, and syringolin and the ice nucleation gene (Feil et al. 2005).

\section{The T3SS of Psy642 is only distantly related to all previously described Pseudomonas spp. T3SS.}

Many variants of the T3SS exist in the genus Pseudomonas (Hueck 1998; Preston et al. 2001). To determine whether the Psy642 $\mathrm{hrp} / \mathrm{hrc}$ locus is closely related to any previously described T3SS gene cluster in a different Pseudomonas sp. and, thus, might have been acquired from that species by horizontal gene transfer, sequences for a core genome protein $(\mathrm{GyrB})$ and a T3SS structural protein ( $\mathrm{HrCC}$ ) were compared between the three completely sequenced $P$. syringae strains and strains of other Pseudomonas spp. Several representatives of the close relative of $P$. syringae, $P$. viriflava, were also examined because this species has a polymorphic T3SS (Araki et al. 2006). Some $P$. viridiflava strains have an $h r p / h r c$ locus similar to the $P$. cichorii T3SS. This locus is named S-PAI (single pathogenicity island) because it does not have the typical tripartite organization of the $P$. syringae $h r p / h r c$ cluster. It is missing the flanking EEL and CEL loci and, like Psy642, has the avrE1 gene and its chaperone $a v r F l$ inserted between $h r c U$ and $h r p V$. Other $P$. viridiflava strains, instead, have a typical tripartite $P$. syringae hrp/hrc locus, including the flanking CEL and EEL loci. This locus is named T-PAI (tripartite PAI). Because the Psy642 hrp/hrc cluster has an organization similar to the hrp/hrc cluster of the $P$. viridiflava and $P$. chicorii S-PAI, we hypothesized that multiple S-PAI of these species might be the closest relatives of the Psy642 hrp/hrc cluster. However, as can be seen from the neighbor-joining tree for $\mathrm{HrcC}$ (Fig. 4A), HrcCPsy642 is different from all other HrcC proteins and clusters basal to $\mathrm{HrcC}$ of $P$. syringae and $P$. viridiflava strains 1 and 3. As expected from the MLSA tree in Figure 1, Psy642 clusters with the other $P$. syringae strains in the GyrB tree shown in Figure 4B. Because the GyrB protein is so similar between most strains in the tree and, therefore, a distinct phylogeny supported by high bootstrap values could not be obtained, a similar tree based on DNA sequence alignment of $g y r B$ was also built (Supplementary Fig. 6). This tree has a higher resolution and confirms the GyrB tree. Although it is impossible to identify an obvious donor of the Psy642 hrp/hrc cluster from these data, the very different position of Psy642 in relation to the other $P$. syringae strains in the $\mathrm{HrcC}$ tree compared with the gyrB tree suggests that the Psy642 hrp/hrc cluster and the canonical $h r p / h r c$ cluster are not derived by vertical descent from a single $h r p / h r c$ cluster in the most recent common ancestor (MRCA) of all $P$. syringae.

\section{The Psy642 T3SS is functional but}

\section{has no apparent role during in planta growth.}

A luciferase reporter assay was used to determine whether or not the T3SS of Psy642 might be controlled similarly to the T3SS of regular $P$. syringae strains despite the differences discussed above. A luciferase construct (kindly provided by Dr. Zhou, China Agricultural University, Beijing, China) fused to the HrpL-regulated Hrp box-containing avrPtol promoter (Xiao et al. 2004) was ectopically expressed in Psy642 and, as a control, in PsyB728a. Strains were grown in rich medium (that represses expression of the $P$. syringae T3SS and effec- tors) and in minimal medium (that induces HrpL-dependent expression of the $P$. syringae T3SS and effectors) (Huynh et al. 1989). As expected, in PsyB728a, the avrPtol promoter was strongly induced only in minimal medium (Fig. 5A). However, when the same construct was expressed in Psy642, strong luciferase activity was detected in both minimal and rich medium (Fig. 5A). Luciferase activity was even higher in rich compared with minimal medium. No luciferase activity was detected in either the absence of the substrate luciferin or the absence of bacteria with the avrPtol-luciferase construct. These data suggest that Psy642 does not limit T3SS and effector expression to in planta conditions.

Because bacteria expressing avrRpt 2 elicit an HR (visible as collapse of the infiltrated leaf area) in A. thaliana ecotype Columbia only upon T3SS-dependent translocation into plant cells (Leister et al. 1996), the effector gene avrRpt2 was ectopically expressed from the Psy642 genome using the integration plasmid pVT359 (Mohr et al. 2008) to establish the functionality of Psy642's T3SS. When infiltrated into A. thaliana Columbia, Psy642 expressing avrRpt2 caused tissue collapse $24 \mathrm{~h}$ later in the majority of leaves (Fig. 5B). However, the HR was weaker and delayed compared with the HR caused by PtoDC3000 (which has a canonical hrp/hrc cluster) (Alfano et al. 2000) expressing avrRpt2 (data not shown). Leaf collapse was only observed for a minority of leaves when Psy642 expressing avrRpt2 was infiltrated into mutant plants that do not recognize AvrRpt 2 because of a mutation in the RPS2 resistance gene (Mindrinos et al. 1994) or when Psy642 harboring the empty vector pVT138 (Mohr et al. 2008) was infiltrated into leaves (Fig. 5B). Therefore, Psy642 appears to be able to translocate AvrRpt 2 into A. thaliana cells. This result was unexpected because the group 2c $P$. syringae isolate Psy508 expressing avrRpt2 had not caused leaf collapse in a similar experiment (Mohr et al. 2008). However, the previous HR test for Psy508 had been performed by growing plants in a different growth chamber with different lights, resulting in hardier leaves than the leaves in the HR test performed here. Also, a lower infection dose had been used $\left(\mathrm{OD}_{600}\right.$ of 0.1 compared with $\mathrm{OD}_{600}$ of 0.3 ). When the HR experiment was repeated with Psy508 under the new conditions, Psy508 caused collapse of many leaves also when carrying an empty vector and on rps 2 mutant plants (data not shown), making it impossible to determine AvrRpt2 translocation. This propensity of Psy508 to cause leaf collapse was previously observed in $N$. benthamiana (Mohr et al. 2008). However, when Psy508 expressing avrRpt2 was infiltrated at low dose in $N$. benthamiana, it caused small HR specks (Mohr et al. 2008), whereas wild-type Psy508 did not, which is in agreement with an ability of group 2c $P$. syringae to translocate AvrRpt 2 into plant cells.

To confirm that AvrRpt2 was translocated from Psy642 into plant cells through the identified noncanonical T3SS, putative T3SS-deficient derivatives of Psy642 were created by disrupting the $h r c C$ gene, a gene coding for an essential component of the T3SS and commonly used to disrupt type III secretion (Guttman et al. 2002). The plasmid pLH12 (Whalen et al. 1991) carrying avrRpt 2 was then added to two $h r c C$ disruption strains derived from two independent recombination events. avrRpt2, expressed in a Psy642 strain with a chromosomal integration of the empty plasmid pVT138 (Mohr et al. 2008), was used as control. The ability of the Psy642 $h r c C$ disruption strains to cause leaf collapse on A. thaliana Columbia when expressing avrRpt 2 was reduced to the same background level caused by the control strain on the A. thaliana rps 2 mutant (Fig. 5C). Therefore, translocation of AvrRpt2 from Psy642 into plant cells appears to be dependent on the Psy642 $\mathrm{hrp} / \mathrm{hrc}$ cluster. The fact that only 11 of 20 leaves infiltrated with the control strain expressing avrRpt2 from the pLH12 plasmid 
caused leaf collapse (Fig. 5C) whereas 9 of 10 leaves infiltrated with Psy642 expressing avrRpt 2 from the chromosome caused leaf collapse (Fig. 5B) is not surprising, because we previously observed that single-copy chromosomally encoded avrRpt 2 causes a stronger HR than avrRpt 2 expressed from the pLH12 plasmid (Guttman and Greenberg 2001).

The Psy642 hrcC disruption strains were then compared with wild-type Psy642 in regard to growth on $N$. benthamiana, bean, and $A$. thaliana. Surprisingly, bacterial population sizes were indistinguishable between the wild-type strain and the $h r c C$ disruption strains 3 days postinfection (Fig. 5D and data not shown).

\section{DISCUSSION}

It was well known that $P$. syringae represents a very diverse group of plant pathogens causing disease on dozens of different plant species with the aid of a wide variety of different effectors and toxins. However, one commonality between all $P$. syringae pathogens appeared to be the $h r p / h r c$ cluster encoding a T3SS and the flanking conserved and exchangeable effector loci (Alfano et al. 2000). Manipulation of plant cells by effector proteins to suppress plant immunity was considered to be a hallmark of $P$. syringae pathogenesis; however, there have been reports of nonpathogenic $P$. syringae that do not cause disease on any plant (Lindow 1985; Hirano and Upper 2000).

Previous work characterized $P$. syringae strains that apparently did not have a T3SS and were nonpathogenic on any tested plant species (Mohr et al. 2008). Here, we have shown that these unusual $P$. syringae strains belong to a phylogenetic subgroup that is very common on healthy plants. Surprisingly, though, these strains actually contain an hrp/hrc cluster and putative effectors. Importantly, our finding that the group $2 \mathrm{c}$ isolate Psy642 causes an RPS2-dependent HR (although delayed and weak) in A. thaliana when expressing the effector gene avrRpt 2 while a Psy642 strain with a disruption of the conserved T3SS gene $h r c C$ does not, strongly suggests that the Psy642 T3SS is functional. However, two genes that are part of the canonical $P$. syringae hrp/hrc cluster are missing: hrpK and $h r p S$. Also, two operons in the Psy642 hrp/hrc cluster only have partially conserved Hrp boxes, which are known to be required for HrpL-dependent (T3SS-associated) expression of downstream genes in other $P$. syringae strains (Xiao and Hutcheson 1994). Therefore, the Psy642 hrp/hrc cluster may be expressed only weakly because of imperfect or missing Hrp boxes, and the T3SS may only inefficiently translocate effectors because of the absence of $h r p K$. This may explain the weak and delayed HR caused by Psy642 when expressing avrRpt2 during infection of $A$. thaliana.

Interestingly, deletion of either $h r p S$ or $h r p R$ was found to abolish $h r p L$ expression in $P$. syringae (Lan et al. 2007) but Psy642 expresses the HrpL-dependent promoter of the PtoDC3000 effector avrPtol in rich and minimum medium, although there is no hrpS locus. HrpR and HrpS are enhancerbinding proteins that interact with each other to induce transcription of $h r p L$ (Hutcheson et al. 2001). One explanation for the fact that $\mathrm{HrpL}_{\mathrm{Psy} 642}$ appears to be expressed in the absence of $h r p S$ may lay in the fact that $h r p R$ and $h r p S$ have similar sequences and, thus, one might have evolved by duplication from the other. Therefore, it is possible that $\mathrm{HrpR}_{\mathrm{Psy642}}$ is the progenitor of $\mathrm{HrpR}$ and $\mathrm{HrpS}$ encoded by the canonical hrp/hrc cluster and can form a homomeric complex whereas, in other $P$. syringae strains, HrpR can only form a heteromeric complex with HrpS to activate transcription of $h r p L$.

HrpR and HrpS protein levels are regulated by the Lon protease and deletion of lon protease has opposite effects in rich versus minimum medium, increasing $h r p L$ expression in rich medium and abolishing it in minimum medium (Lan et al. 2007). Therefore, we hypothesize that the activity of the HrpLdependent avrPtol promoter in group 2c P. syringae bacteria in rich medium may be due to a different regulation of $\mathrm{HrpR}_{\mathrm{Psy} 642}$ by Lon protease compared with other $P$. syringae strains.

Because the phylogenetic position of Psy642 in the gyrB tree is markedly different from its position in the $\mathrm{HrcC}$ tree (Fig. 4), the two types of $P$. syringae hrp/hrc clusters were probably acquired in separate evolutionary events. However, at this point, we can only speculate as to whether the MRCA of all $P$. syringae had one or the other $h r p / h r c$ cluster and whether the MRCA of group 2c P. syringae lost the canonical hrp/hrc cluster and acquired the Psy642-like cluster, or if the MRCA of all other P. syringae lost the Psy642-like cluster and acquired the canonical cluster. Nonetheless, the absence of $h r p S$ and $h r p K$ suggests that the Psy642 hrp/hrc cluster is more primitive than the canonical hrp/hrc cluster and, thus, that the Psy642 hrp/hrc cluster may be more similar to the ancestor of both of these clusters.

In addition to the differences in the hrp/hrc cluster, the other striking difference between group 2c $P$. syringae and other $P$. syringae is the difference in their effector repertoires. The only shared effector genes are avrEl and hopM1. Moreover, $a v r E 1_{\mathrm{Psy} 642}$ and $h o p M 1_{\mathrm{Psy} 642}$ are only very distantly related to their homologues in other $P$. syringae strains. Comparing AvrE1 $_{\text {Psy642 }}$ with AvrE1 homologues from $P$. syringae, $P$. viridiflava, P. cichorii, and even P. fluorescens, and Erwinia and Pantoea spp. in GenBank revealed that AvrE $1_{\mathrm{Psy}_{642}}$ has two regions (approximately from position 500 to 700 and from position 1,350 to 1,550 ) that are so divergent that they do not align with any AvrE1 homologue (whereas AvrE1 $1_{\mathrm{PtoDC} 3000}$, for example, aligns with AvrE1 homologues of $P$. syringae and $P$. viridiflava strains over its entire length and from position 221 to its $\mathrm{C}$ terminus with all other homologues besides AvrE1 $1_{\text {Psy642 }}$ ). Ham and associates (2009) recently found that AvrE1 homologues from $P$. syringae, Pantoea stewartii, and other hemibiotrophs have two WxxxE motifs necessary to suppress callose deposition and to induce cell death. They noted that WxxxE motifs are also present in effectors of mammalian pathogens and appear to mimic activated Ras-like GTPases. However, similarly to the AvrE1 homologues of Pseudomonas viridiflava and Pectobacterium atrosepticum (Ham et al. 2009), AvrE1 $1_{\mathrm{Psy} 642}$ does not have any WxxxE motifs, suggesting that it may not function in either suppression of plant defenses or cell death induction.

In addition to suppressing MTI, AvrE1 $1_{\mathrm{PtoDC} 3000}$ also triggers an $\mathrm{HR}$ in soybean (Lorang and Keen 1995) and HopM1 $1_{\mathrm{PtoDC} 3000}$ contributes to lesion formation during disease on tomato (Badel et al. 2003) and causes necrosis on several plants when transiently expressed in Agrobacterium spp.-mediated assays (Wroblewski et al. 2009). Also, the putative Psy642 effector with homology to ExoY could possibly trigger immunity in some plants. In fact, an ExoY homologue from the biocontrol strain Pseudomonas fluorescens SBW25 (Vinatzer et al. 2005) was found to induce necrosis indicative of an HR on many tomato and lettuce cultivars when transiently expressed in Agrobacterium spp.-mediated assays (Wroblewski et al. 2009). It is also possible that some of the putative effectors flanking the Psy642 hrp/hrc cluster and possibly other putative type III effectors in the Psy642 genome trigger plant immunity. However, the fact that the T3SS-deficient hrcC mutant strains of Psy642 grow to indistinguishable population densities compared with wildtype Psy642 on N. benthamiana, bean, and A. thaliana suggests that effector-dependent suppression or elicitation of plant immunity may play only a minor role in the interaction of group 2c strains with plants and in the observed host preference of group 2c strains for $N$. benthamiana and bean over A. thaliana. Instead, T3SS-independent mechanisms may be important deter- 
minants of host preference in this group. However, we cannot yet exclude that the Psy642 T3SS and effectors may play a role in the interaction with other plant species.

At this point, there is not enough evidence to definitely claim that group 2c P. syringae are either pathogens or nonpathogens of plants. On the one hand, all identified strains have a $h r p / h r c$ cluster, putative effectors, and genes for the synthesis of the phytotoxin syringomycin (data not shown). At least one group 2c strain, Psy508, also produces syringopeptin (Grgurina et al. 2005) and the Psy642 genome encodes the gene cluster for its synthesis. Therefore, group 2c strains are equipped with known virulence factors, suggesting their pathogenic nature. On the other hand, all group 2c P. syringae have been isolated from healthy plants, did not cause disease on any tested plant species (PsyTLP2 was found to be nonpathogenic on 50 plant species by Lindow [1985]), their T3SS does not seem to be necessary for in planta growth, and they have never been identified as causal agents of any plant diseases, which suggests their nonpathogenic nature. Moreover, the presence of the ice nucleation activity gene in all analyzed group $2 \mathrm{c}$ strains suggests that their life cycle might be connected to the water cycle (Morris et al. 2008) (i.e., group 2c strains may be transported with air currents to clouds, catalyze ice formation, and return to plant surfaces with snow and rain). Ability to colonize many different plant species would be particularly advantageous with such a mode of transmission whereas being a host-restricted pathogen equipped with effectors that trigger plant defenses on many plant species would limit their chance of completing their life cycle. Being a generalist nonpathogen would also favor insect transmission because healthy leaves may be preferred by insects over sick leaves. The observations that PsyB728a has recently been found to cause disease in aphids (Stavrinides et al. 2009) and PsyB728a, the genome of Psy642, contains genes for toxins that are shared with insect pathogens such as AprA (Liehl et al. 2006) and XaxAB (Vigneux et al. 2007) (data not shown), speak in support of this hypothesis. Moreover, the fact that the Psy642 T3SS is expressed in rich medium and does not appear to play a major role during in planta growth on either $N$. benthamiana, bean, or A. thaliana suggests that Psy642 might interact as pathogen (or as commensal) with nonplant hosts and that its T3SS may play an important role in these interactions.

Identifying and characterizing the complete Psy642 effector repertoire and further investigating the role of the $\mathrm{hrp} / \mathrm{hrc}$ cluster in the interaction of Psy642 with additional plant species and nonplant hosts will be the next steps to understand the intriguing biology of group $2 \mathrm{c} P$. syringae bacteria.

\section{MATERIALS AND METHODS}

\section{Isolation of bacterial strains.}

Bacterial isolation was performed as previously described (Mohr et al. 2008) except that homogenates were plated on agar plates of King's medium B (KB) modified with cephalexin and boric acid (KBC) (Mohan and Schaad 1987) instead of $\mathrm{KB}$ plates containing nitrofurantoin. All P. syringae and Escherichia coli strains were grown as previously described (Mohr et al. 2008).

\section{Phylogenetic tree construction.}

DNA sequences for MLSA were obtained as previously described (Hwang et al. 2005). Allele sequences and allelic profiles were added to the PAMDB website (Almeida et al. in press) together with metadata for each isolate. Concatenated locus sequences were downloaded and a neighbor-joining tree (Fig. 1) was constructed in Megalign of the Lasergene package (DNA*, Madison, WI, U.S.A.). Bootstrapping was performed using 1,000 trials and a random seed value of 111 . To construct phylogenetic trees of proteins, edited protein sequences were first aligned in BioX 1.0b2 to $1.1 \mathrm{~b} 1$ (BioX website) using ClustalW 1.83. The tree was then constructed in Megalign as above. To create the $\operatorname{gyr} B$ tree, edited DNA sequences were aligned in BioX as above. Then trees were constructed and bootstrapped in PAUP* 4.0b10 (Swofford 2003) using 1,000 bootstrapping trials.

\section{Plant growth conditions and bacterial growth assays.}

Plants were grown in a Percival Scientific CU-32L growth chamber (Perry, IA, U.S.A.) in SunGro Sunshine mix 1 (SunGro Horticulture Inc., Seba Beach, Canada) under 16-h days at $22^{\circ} \mathrm{C}$ and infected when 3 to 4 weeks old $(2.5$ weeks old for bean). All in planta bacterial growth assays were done as previously described (Mohr et al. 2008) with minor modifications: inoculum doses for $N$. benthamiana and bean cv. Red Mexican corresponded to an $\mathrm{OD}_{600}$ of 0.001 ; for tomato cv. Chico III, the $\mathrm{OD}_{600}$ was 0.01 ; and, for A. thaliana cv. Columbia-0, the $\mathrm{OD}_{600}$ was 0.1. The surfactant Silwet L-77 (Lehle Seeds, Round Rock, TX, U.S.A.) was added to all bacterial suspensions to a final concentration of $0.025 \%$ ( $\mathrm{vol} / \mathrm{vol})$. Leaf tissue samples were punched out of the infected plants using the blunt end of a pipette tip for A. thaliana or the top of a $1.5-\mathrm{ml}$ centrifuge tube for $N$. benthamiana, bean, and tomato (representing 0.35 and $0.52 \mathrm{~cm}^{2}$ of leaf area respectively). To determine "total" bacterial growth, leaf punches were pestle ground without prior sterilization. To distinguish between endophytic and epiphytic growth, leaf punches were placed in $200 \mu \mathrm{l}$ of $10 \mathrm{mM}$ $\mathrm{MgSO}_{4}$ in a $1.5-\mathrm{ml}$ centrifuge tube and vortexed using a Fisher Vortex Genie 2 for $20 \mathrm{~s}$ to remove epiphytic bacteria from the leaf surface (Guttman and Greenberg 2001). Leaf punches were then transferred to a new 1.5-ml centrifuge tube with 200 $\mu \mathrm{l}$ of $10 \mathrm{mM} \mathrm{MgSO}_{4}$ and ground thoroughly to release the endophytic bacteria. All bacterial suspensions were serial diluted on KBC plates (Mohan and Schaad 1987). Statistical analysis was performed using SAS JMP 7 (SAS Institute, Cary, NC, U.S.A.). For HR assays, strains were infiltrated into half leaves at a concentration corresponding to an $\mathrm{OD}_{600}$ of 0.3 . The bacterial suspension was infiltrated into the left half of leaves of 4week-old $A$. thaliana plants. The number of leaves exhibiting characteristic HR-associated leaf collapse was quantified 22 to $24 \mathrm{~h}$ later.

\section{Genome sequencing and analysis.}

Psy642 was sequenced via paired-end sequencing with 42bp-long reads on two channels of an Illumina GA-II producing $8,477,656$ high-quality clusters with an insert size of approximately $150 \mathrm{bp}$. The primary image data was analyzed using the GA Pipeline version 1.0. Sequence data were assembled using Velvet 0.7.18 (Zerbino and Birney 2008). The previously published sequence of PsyB728a (Feil et al. 2005) was downloaded from the National Center for Biotechnology Information (NCBI) FTP site. Illumina reads were aligned against the PsyB728a genome using the MAQ software (Li et al. 2008). The Psy642 assembly was searched for matches to canonical Hrp boxes and sigma (54)-dependent promoters using the HMMER 1.8.5 package. The hidden Markov Model (HMM) for the Hrp box was previously described (Studholme et al. 2009). The RpoN HMM was built from the compilation of 186 sigma (54)-dependent promoters described by Barrios and associates (1999).

\section{Luciferase assay.}

Plasmids containing avrPto-luc (Xiao et al. 2004) were kindly provided by Dr. Zhou, State Key Laboratory of Plant Physiology and Biochemistry, China Agricultural University, 
Beijing, China. Plasmids were conjugated into PsyB728a and Psy642 as previously described (Guttman et al. 2002). The four resulting strains were grown overnight in liquid $\mathrm{KB}$ or minimal medium at $28^{\circ} \mathrm{C}$ with shaking at $200 \mathrm{rpm}$. All overnight cultures were diluted to the same concentration and 150 $\mu \mathrm{l}$ was aliquoted into individual wells of a 96-well plate. Luciferin was added to a concentration of $10 \mu \mathrm{M}$ and the reaction was allowed to proceed for $15 \mathrm{~min}$. An intensified charge-coupled device video camera (model C2400 47; Hamamatsu Photonics, Hamamatsu City, Japan) in combination with an Image Intensifier Controller (model M4314; Hamamatsu Photonics) and Image Processor (Argus 50; Hamamatsu Photonics) was used to measure luciferase activity.

\section{hrcC gene disruption.}

A primer pair was designed to amplify a central 500-bp-long fragment of the $h r c C_{\mathrm{Psy} 642}$ gene. In-frame stop codons were added to the $5^{\prime}$ end of the primers, an ApaI site to one primer and a ClaI site to the other primer. The fragment was cloned into pBAV208 and two E. coli colonies were confirmed to contain the correct fragment (plasmids pVT1097 and pVT1098). These plasmids were then introduced into Psy642 to disrupt $h r c C_{\mathrm{Psy642}}$ using the same procedure as previously described (Mohr et al. 2008). Strains P. syringae VT1112 and VT1113 were obtained. These strains each contain two $h r c C$ fragments, one $5^{\prime}$ fragment with a stop at codon 417 and one $3^{\prime}$ fragment starting with a stop codon at position 242 .

\section{ACKNOWLEDGMENTS}

This work was supported by the National Science Foundation (award number 0746501). We thank undergraduate students from Concord University (Athens, WV, U.S.A.), under the supervision of D. Wise, and high school students from Roanoke Valley Governor School for Science and Technology, under the supervision of J. Kowalski, for help with collecting plants and isolating bacteria; T. Wieboldt, curator of the Virginia Tech herbarium, for identifying plant species from which bacteria were isolated; B. Gunesekera for help with the luciferase assay; and J. Jelesko for letting us use his intensified charge-coupled device video camera for measuring luciferase activity.

\section{LITERATURE CITED}

Agrios, G. 1997. Plant Pathology. Academic Press, San Diego, CA, U.S.A. Alfano, J. R., Charkowski, A. O., Deng, W. L., Badel, J. L., PetnickiOcwieja, T., van Dijk, K., and Collmer, A. 2000. The Pseudomonas syringae Hrp pathogenicity island has a tripartite mosaic structure composed of a cluster of type III secretion genes bounded by exchangeable effector and conserved effector loci that contribute to parasitic fitness and pathogenicity in plants. Proc. Natl. Acad. Sci. U.S.A. 97:48564861.

Almeida, N. F., Yn, S., Cai, R., Clarke, C. R., Morris, C. E., Schaad, N. W., Lacy, G. H., Jones, J. B., Castillo, J. A., Bull, C. T., Leman, S., Guttman, D. S., Setubal, J. C., Vinatzer, B. A. PAMDB, a multilocus sequence typing $\&$ analysis database and website for plant-associated and plant-pathogenic mocroorganisms. Phytopathology. In press.

Altschul, S. F., Madden, T. L., Schaffer, A. A., Zhang, J., Zhang, Z., Miller, W., and Lipman, D. J. 1997. Gapped BLAST and PSI-BLAST: A new generation of protein database search programs. Nucleic Acids Res. 25:3389-3402.

Araki, H., Tian, D., Goss, E. M., Jakob, K., Halldorsdottir, S. S., Kreitman, M., and Bergelson, J. 2006. Presence/absence polymorphism for alternative pathogenicity islands in Pseudomonas viridiflava, a pathogen of Arabidopsis. Proc. Natl. Acad. Sci. U.S.A. 103:5887-5892.

Badel, J. L., Nomura, K., Bandyopadhyay, S., Shimizu, R., Collmer, A., and He, S. Y. 2003. Pseudomonas syringae pv. tomato DC3000 HopPtoM (CEL ORF3) is important for lesion formation but not growth in tomato and is secreted and translocated by the Hrp type III secretion system in a chaperone-dependent manner. Mol. Microbiol. 49:12391251.

Barrios, H., Valderrama, B., and Morett, B. 1999. Compilation and analysis of sigma(54)-dependent promoter sequences. Nucleic Acids Res. 27 (22):4305-4313.
Bender, C. L., Alarcon-Chaidez, F., and Gross, D. C. 1999. Pseudomonas syringae phytotoxins: Mode of action, regulation, and biosynthesis by peptide and polyketide synthetases. Microbiol. Mol. Biol. Rev. 63:266292.

Bentley, D. R. 2006. Whole-genome re-sequencing. Curr. Opin. Genet. Dev. 16:545-552.

Buell, C. R., Joardar, V., Lindeberg, M., Selengut, J., Paulsen, I. T., Gwinn, M. L., Dodson, R. J., Deboy, R. T., Durkin, A. S., Kolonay, J. F. Madupu, R., Daugherty, S., Brinkac, L., Beanan, M. J., Haft, D. H., Nelson, W. C., Davidsen, T., Zafar, N., Zhou, L., Liu, J., Yuan, Q., Khouri, H., Fedorova, N., Tran, B., Russell, D., Berry, K., Utterback, T., Van Aken, S. E., Feldblyum, T. V., D’Ascenzo, M., Deng, W. L., Ramos, A. R., Alfano, J. R., Cartinhour, S., Chatterjee, A. K., Delaney, T. P., Lazarowitz, S. G., Martin, G. B., Schneider, D. J., Tang, X., Bender, C. L., White, O., Fraser, C. M., and Collmer, A. 2003. The complete genome sequence of the Arabidopsis and tomato pathogen Pseudomonas syringae pv. tomato DC3000. Proc. Natl. Acad. Sci. U.S.A 100:10181-10186.

Burr, T. J., Matteson, M. C., Smith, C. A., Corral-Garcia, M. R., and Huang, T. C. 1996. Effectiveness of bacteria and yeasts from apple orchards as biological control against apple scab. Biol. Control 6:151-157.

Charity, J. C., Pak, K., Delwiche, C. F., and Hutcheson, S. W. 2003. Novel exchangeable effector loci associated with the Pseudomonas syringae hrp pathogenicity island: Evidence for integron-like assembly from transposed gene cassettes. Mol. Plant-Microbe Interact. 16:495-507.

Charkowski, A. O., Alfano, J. R., Preston, G., Yuan, J., He, S. Y., and Collmer, A. 1998. The Pseudomonas syringae pv. tomato HrpW protein has domains similar to harpins and pectate lyases and can elicit the plant hypersensitive response and bind to pectate. J. Bacteriol. 180:5211-5217.

Chisholm, S. T., Coaker, G., Day, B., and Staskawicz, B. J. 2006. Host-microbe interactions: Shaping the evolution of the plant immune response. Cell 124:803-814.

DebRoy, S., Thilmony, R., Kwack, Y. B., Nomura, K., and He, S. Y. 2004. A family of conserved bacterial effectors inhibits salicylic acid-mediated basal immunity and promotes disease necrosis in plants. Proc. Natl. Acad. Sci. U.S.A. 101:9927-9932.

Deng, W. L., Rehm, A. H., Charkowski, A. O., Rojas, C. M., and Collmer, A. 2003. Pseudomonas syringae exchangeable effector loci: Sequence diversity in representative pathovars and virulence funcion in $P$. syringae pv. syringae B728a. J. Bacteriol. 185:2592-2602.

Feil, H., Feil, W. S., Chain, P., Larimer, F., DiBartolo, G., Copeland, A., Lykidis, A., Trong, S., Nolan, M., Goltsman, E., Thiel, J., Malfatti, S. Loper, J. E., Lapidus, A., Detter, J. C., Land, M., Richardson, P. M., Kyrpides, N. C., Ivanova, N., and Lindow, S. E. 2005. Comparison of the complete genome sequences of Pseudomonas syringae pv. syringae B728a and pv. tomato DC3000. Proc. Natl. Acad. Sci. U.S.A. 102:11064-11069.

Finck-Barbancon, V., Goranson, J., Zhu, L., Sawa, T., Wiener-Kronish, J. P., Fleiszig, S. M., Wu, C., Mende-Mueller, L., and Frank, D. W. 1997. ExoU expression by Pseudomonas aeruginosa correlates with acute cytotoxicity and epithelial injury. Mol. Microbiol. 25:547-557.

Fouts, D. E., Abramovitch, R. B., Alfano, J. R., Baldo, A. M., Buell, C. R., Cartinhour, S., Chatterjee, A. K., D'Ascenzo, M., Gwinn, M. L., Lazarowitz, S. G., Lin, N. C., Martin, G. B., Rehm, A. H., Schneider, D. J., van Dijk, K., Tang, X., and Collmer, A. 2002. Genomewide identification of Pseudomonas syringae pv. tomato DC3000 promoters controlled by the HrpL alternative sigma factor. Proc. Natl. Acad. Sci. U.S.A. 99:2275-2280.

Gevers, D., Cohan, F. M., Lawrence, J. G., Spratt, B. G., Coenye, T., Feil, E. J., Stackebrandt, E., Van de Peer, Y., Vandamme, P., Thompson, F. L., and Swings, J. 2005. Opinion: Re-evaluating prokaryotic species. Nat. Rev. Microbiol. 3:733-739.

Greenberg, J. T., and Yao, N. 2004. The role and regulation of programmed cell death in plant-pathogen interactions. Cell Microbiol. 6:201-211.

Grgurina, I., Bensaci, M., Pocsfalvi, G., Mannina, L., Cruciani, O., Fiore, A., Fogliano, V., Sorensen, K. N., and Takemoto, J. Y. 2005. Novel cyclic lipodepsipeptide from Pseudomonas syringae pv. lachrymans strain 508 and syringopeptin antimicrobial activities. Antimicrob. Agents Chemother. 49:5037-5045.

Guttman, D. S., and Greenberg, J. T. 2001. Functional analysis of the type III effectors AvrRpt2 and AvrRpm1 of Pseudomonas syringae with the use of a single-copy genomic integration system. Mol. Plant-Microbe Interact. 14:145-155.

Guttman, D. S., Vinatzer, B. A., Sarkar, S. F., Ranall, M. V., Kettler, G., and Greenberg, J. T. 2002. A functional screen for the type III (Hrp) secretome of the plant pathogen Pseudomonas syringae. Science 295:1722-1726.

Ham, J. H., Majerczak, D. R., Nomura, K., Mecey, C., Uribe, F., He, S. Y., Mackey, D., and Coplin, D. L. 2009. Multiple activities of the plant 
pathogen type III effector proteins WtsE and AvrE require WxxxE motifs. Mol. Plant-Microbe Interact. 22:703-712.

Hirano, S. S., and Upper, C. D. 2000. Bacteria in the leaf ecosystem with emphasis on Pseudomonas syringae - a pathogen, ice nucleus, and epiphyte. Microbiol. Mol. Biol. Rev. 64:624-653.

Huang, H. C., Xiao, Y., Lin, R. H., Lu, Y., Hutcheson, S. W., and Collmer, A. 1993. Characterization of the Pseudomonas syringae pv. syringae 61 hrpJ and hrpI genes: Homology of HrpI to a superfamily of proteins associated with protein translocation. Mol. Plant-Microbe Interact. 6:515-520.

Hueck, C. J. 1998. Type III protein secretion systems in bacterial pathogens of animals and plants. Microbiol. Mol. Biol. Rev. 62:379-433.

Hutcheson, S. W., Bretz, J., Sussan, T., Jin, S., and Pak, K. 2001. Enhancer-binding proteins HrpR and HrpS interact to regulate hrp-encoded type III protein secretion in Pseudomonas syringae strains. J. Bacteriol. 183:5589-5598

Huynh, T. V., Dahlbeck, D., and Staskawicz, B. J. 1989. Bacterial blight of soybean: Regulation of a pathogen gene determining host cultivar specificity. Science 245:1374-1377.

Hwang, M. S., Morgan, R. L., Sarkar, S. F., Wang, P. W., and Guttman, D. S 2005. Phylogenetic characterization of virulence and resistance phenotypes of Pseudomonas syringae. Appl. Environ. Microbiol. 71:5182-5191.

Jones, J. D., and Dangl, J. L. 2006. The plant immune system. Nature 444:323-329.

Lan, L., Deng, X., Xiao, Y., Zhou, J. M., and Tang, X. 2007. Mutation of Lon protease differentially affects the expression of Pseudomonas syringae type III secretion system genes in rich and minimal media and reduces pathogenicity. Mol. Plant-Microbe Interact. 20:682-696.

Leister, R. T., Ausubel, F. M., and Katagiri, F. 1996. Molecular recognition of pathogen attack occurs inside of plant cells in plant disease resistance specified by the Arabidopsis genes RPS2 and RPM1. Proc. Natl. Acad. Sci. U.S.A. 93:15497-15502.

Li, H., Ruan, J., and Durbin, R. 2008. Mapping short DNA sequencing reads and calling variants using mapping quality scores. Genome Res. 18:1851-1858.

Liehl, P., Blight, M., Vodovar, N., Boccard, F., and Lemaitre, B. 2006. Prevalence of local immune response against oral infection in a Drosophila/Pseudomonas infection model. PLoS Pathog. 2:e56.

Lindeberg, M., Myers, C. R., Collmer, A., and Schneider, D. J. 2008. Roadmap to new virulence determinants in Pseudomonas syringae: Insights from comparative genomics and genome organization. Mol. PlantMicrobe Interact. 21:685-700.

Lindow, S. E. 1985. Ecology of Pseudomonas syringae relevant to the field use of ice-deletion mutants constructed in vitro for plant frost control. Pages 23-35 in: Engineered Organisms in the Environment: Scientific Issues. H. O. Halvorson, D. Pramer, and M. Rogul, eds. American Society for Microbiology, Washington, D.C.

Lindow, S. E., Arny, D. C., and Upper, C. D. 1982. Bacterial ice nucleation: A factor in frost injury to plants. Plant Physiol. 70:1084-1089.

Lorang, J. M., and Keen, N. T. 1995. Characterization of avrE from Pseudomonas syringae pv. tomato: A hrp-linked avirulence locus consisting of at least two transcriptional units. Mol. Plant-Microbe Interact. 8:4957.

Maiden, M. C., Bygraves, J. A., Feil, E., Morelli, G., Russell, J. E., Urwin, R., Zhang, Q., Zhou, J., Zurth, K., Caugant, D. A., Feavers, I. M., Achtman, M., and Spratt, B. G. 1998. Multilocus sequence typing: A portable approach to the identification of clones within populations of pathogenic microorganisms. Proc. Natl. Acad. Sci. U.S.A. 95:31403145 .

McCarter, S. M., Jones, J. B., Gitaitis, R. D., and Smitley, D. R. 1983. Survival of Pseudomonas syringae pv. tomato in association with tomato seeds, soil, host tissue, and epiphytic weed hosts in Georgia. Phytopathology 73:1393-1398.

Mindrinos, M., Katagiri, F., Yu, G. L., and Ausubel, F. M. 1994. The A. thaliana disease resistance gene RPS2 encodes a protein containing a nucleotide-binding site and leucine-rich repeats. Cell 78:1089-1099.

Mohan, S. K., and Schaad, N. W. 1987. An improved agar plating assay for detecting Pseudomonas syringae pv. syringae and $P$. s. pv. phaseolicola in contaminated bean seed. Phytopathology 77:1390-1395.

Mohr, T. J., Liu, H., Yan, S., Morris, C. E., Castillo, J. A., Jelenska, J., and Vinatzer, B. A. 2008. Naturally occurring nonpathogenic isolates of the plant pathogen Pseudomonas syringae lack a type III secretion system and effector gene orthologues. J. Bacteriol. 190:2858-2870.

Morris, C. E., Sands, D. C., Vinatzer, B. A., Glaux, C., Guilbaud, C., Buffiere, A., Yan, S., Dominguez, H., and Thompson, B. M. 2008. The life history of the plant pathogen Pseudomonas syringae is linked to the water cycle. ISME J. 2:321-334.

Oh, H. S., Kvitko, B. H., Morello, J. E., and Collmer, A. 2007. Pseudomonas syringae lytic transglycosylases coregulated with the type III secre- tion system contribute to the translocation of effector proteins into plant cells. J. Bacteriol. 189:8277-8289.

Petnicki-Ocwieja, T., Schneider, D. J., Tam, V. C., Chancey, S. T., Shan, L., Jamir, Y., Schechter, L. M., Janes, M. D., Buell, C. R., Tang, X., Collmer, A., and Alfano, J. R. 2002. Genomewide identification of proteins secreted by the Hrp type III protein secretion system of Pseudomonas syringae pv. tomato DC3000. Proc. Natl. Acad. Sci. U.S.A. 99:7652-7657.

Petnicki-Ocwieja, T., van Dijk, K., and Alfano, J. R. 2005. The hrpK operon of Pseudomonas syringae pv. tomato DC3000 encodes two proteins secreted by the type III (Hrp) protein secretion system: HopB1 and HrpK, a putative type III translocator. J. Bacteriol. 187:649-663.

Preston, G. M., Bertrand, N., and Rainey, P. B. 2001. Type III secretion in plant growth-promoting Pseudomonas fluorescens SBW25. Mol. Microbiol. 41:999-1014.

Stavrinides, J., McCloskey, J. K., and Ochman, H. 2009. Pea aphid as both host and vector for the phytopathogenic bacterium Pseudomonas syringae. Appl. Environ. Microbiol. 75:2230-2235.

Studholme, D. J., Gimenez Ibanez, S., Maclean, D., Dangl, J. L., Chang, J. H., and Rathjen, J. P. 2009. A draft genome sequence and functional screen reveals the repertoire of type III secreted proteins of Pseudomonas syringae pathovar tabaci 11528. BMC Genomics 10 (1):395.

Swofford, D. L. (2003). PAUP* Phylogenetic Analysis Using Parsimony. Sinauer Associates, Sunderland, MA, U.S.A

Vigneux, F., Zumbihl, R., Jubelin, G., Ribeiro, C., Poncet, J., Baghdiguian, S., Givaudan, A., and Brehelin, M. 2007. The $x a x A B$ genes encoding a new apoptotic toxin from the insect pathogen Xenorhabdus nematophila are present in plant and human pathogens. J. Biol. Chem. 282:9571-9580.

Vinatzer, B. A., Jelenska, J., and Greenberg, J. T. 2005. Bioinformatics correctly identifies many type III secretion substrates in the plant pathogen Pseudomonas syringae and the biocontrol isolate $P$. fluorescens SBW25. Mol. Plant-Microbe Interact. 18:877-888.

Whalen, M. C., Innes, R. W., Bent, A. F., and Staskawicz, B. J. 1991. Identification of Pseudomonas syringae pathogens of Arabidopsis and a bacterial locus determining avirulence on both Arabidopsis and soybean. Plant Cell 3:49-59.

Wroblewski, T., Caldwell, K. S., Piskurewicz, U., Cavanaugh, K. A., Xu, H. Kozik, A., Ochoa, O., McHale, L. K., Lahre, K., Jelenska, J., Castillo, J. A., Blumenthal, D., Vinatzer, B. A., Greenberg, J. T., and Michelmore, R. W. 2009. Comparative large-scale analysis of interactions between severa crop species and the effector repertoire from multiple pathovars of Pseudomonas and Ralstonia. Plant Physiol. 150:1733-1749.

Xiao, F., Goodwin, S. M., Xiao, Y., Sun, Z., Baker, D., Tang, X., Jenks, M. A., and Zhou, J. M. 2004. Arabidopsis CYP86A2 represses Pseudomonas syringae type III genes and is required for cuticle development. EMBO (Eur. Mol. Biol. Organ.) J. 23:2903-2913.

Xiao, Y., and Hutcheson, S. W. 1994. A single promoter sequence recognized by a newly identified alternate sigma factor directs expression of pathogenicity and host range determinants in Pseudomonas syringae. J. Bacteriol. 176:3089-3091.

Xiao, Y., Heu, S., Yi, J., Lu, Y., and Hutcheson, S. W. 1994. Identification of a putative alternate sigma factor and characterization of a multicomponent regulatory cascade controlling the expression of Pseudomonas syringae pv. syringae Pss61 hrp and hrmA genes. J. Bacteriol. 176:1025-1036.

Yahr, T. L., Vallis, A. J., Hancock, M. K., Barbieri, J. T., and Frank, D. W. 1998. ExoY, an adenylate cyclase secreted by the Pseudomonas aeruginosa type III system. Proc. Natl. Acad. Sci. U.S.A. 95:13899-13904.

Zerbino, D. R., and Birney, E. 2008. Velvet: Algorithms for de novo short read assembly using de Bruijn graphs. Genome Res. 18:821-829.

Zhou, J. M., and Chai, J. 2008. Plant pathogenic bacterial type III effectors subdue host responses. Curr. Opin. Microbiol. 11:179-185.

Zipfel, C., Robatzek, S., Navarro, L., Oakeley, E. J., Jones, J. D., Felix, G., and Boller, T. 2004. Bacterial disease resistance in Arabidopsis through flagellin perception. Nature 428:764-767.

\section{AUTHOR-RECOMMENDED INTERNET RESOURCES}

BioX site: www.lagercrantz.name/software/biox

HMMER (HMM software for protein sequence analysis) website: hmmer.janelia.org

NCBI FTP site: ftp://ftp.ncbi.nih.gov/genomes/Bacteria/Pseudomonas_ syringae_pv_B728a

PAMDB (Plant associated and environmental microbes database): www.pamdb.org

Pseudomonas syringae genome resources home page: www.pseudomonas-syringae.org

Vinatzer laboratory website: genome.ppws.vt.edu/blast/blast.html 